\title{
A possible role of a specific uterine fluid peptidase in implantation in the rat
}

\author{
M. G. Rosenfeld and M. S. Joshi \\ Department of Anatomy, Downstate Medical Center, Brooklyn, New York, U.S.A.
}

Although the accumulation of uterine fluid during pro-oestrus in the rat has been well documented (Long \& Evans, 1922; Warren, 1938), its exact role in the reproductive process is still not clearly understood. Joshi, Yaron \& Lindner (1970) isolated and characterized an endopeptidase from the uterine luminal fluid of pro-oestrous rats and from immature rats treated with oestrogen. This enzyme was later found to be unique to the uterine fluid and was not found in blood (Joshi \& Murray, 1974). A protein immunologically similar to the rat endopeptidase has also been demonstrated in the uterine washings of oestradiol-treated mice of 3 different strains (Joshi \& Rosenfeld, 1976). The role of this enzyme is unknown, but it has been suggested that this oestrogen-dependent peptidase may play a role in the lysis of the zona pellucida and the penetration of the ovum by the spermatozoon (Joshi \& Murray, 1974).

Since the loss of the zona pellucida is a prerequisite for normal implantation in the rat, the present study was undertaken in an attempt to determine whether (1) the enzyme exhibits any affinity for the zona pellucida, and (2) inhibition of the enzyme has any affect on normal implantation.

\section{Methods}

Wistar rats (Carworth Farms) were maintained in a temperature-controlled environment $(22 \pm$ $1^{\circ} \mathrm{C}$ ) with a $14 \mathrm{~h}$ light : $10 \mathrm{~h}$ dark cycle. Purina rat chow and tap water were freely available.

The uterine peptidase was isolated and purified from rat luminal fluid by the method described by Joshi et al. (1970). The protein content of the purified enzyme was measured by the procedure of Lowry, Rosebrough, Farr \& Randall (1951), using bovine serum albumin (BSA) as the standard.

The antiserum, prepared in rabbits from the purified peptidase as previously described (Joshi \& Murray, 1974), produced one precipitin band during immunodiffusion against the immunizing antigen. The globulin fraction obtained from the antiserum and from normal rabbit serum after $40 \%$ ammonium sulphate saturation was conjugated with fuorescein isothiocyanate (FITC) by the method of Nairn (1969). Fluorescence was observed on a Zeiss microscope using a mercury lamp with BG-12 excitation filter and appropriate secondary filters.

Experiment 1. Immature female rats (22-25 days of age) were injected subcutaneously with 10 i.u. PMSG (Organon) 48-54 h before an intraperitoneal injection of 10-20 i.u. HCG (Life Sciences Pharmaceuticals). The animals were killed by cervical dislocation 12-18 $\mathrm{h}$ after the HCG injection. The ampullae were removed and placed in a large depression slide containing the incubation medium-a modified Krebs-Ringer-bicarbonate solution (Toyoda \& Chang, 1974). The eggs in cumulus mass were dissected out of the ampullae and $1 \mathrm{ml}$ of a solution of $0.1 \%$ hyaluronidase (Sigma Chemical Co.) containing $0 \cdot 1 \%$ BSA was added. The cumulus-free eggs were placed in $1 \mathrm{ml}$ incubation medium containing $0.1 \mathrm{ml}$ purified uterine peptidase $(1.4 \mathrm{mg} / \mathrm{ml})$. The eggs were incubated for $1 \mathrm{~h}$ at room temperature $\left(25^{\circ} \mathrm{C}\right)$ and then washed in incubation medium, fixed in $95 \%$ ethanol, and incubated with the immunoglobulin-FITC(Nairn, 1969). Control eggs were placed in incubation medium which did not contain the peptidase and then processed in a similar manner.

Experiment 2. Portions of uterus and oviduct $(1 \mathrm{~cm})$ were removed on Days 5 and 6 of pregnancy (the presence of spermatozoa or a vaginal plug = Day 1 ) and quickly frozen in isopentane which had been previously cooled with liquid nitrogen. Sections $(8-10 \mu \mathrm{m})$ were cut in a cryostat and fixed in 
$95 \%$ ethanol for $15 \mathrm{~min}$. The fixative was removed by washing in saline and the sections were incubated with immunoglobulin-FITC. Control sections were incubated with unlabelled immunoglobulin before incubating with immunoglobulin-FITC. Alternate sections of the tissue were stained with haematoxylin and eosin.

Experiment 3. Pregnant rats were anaesthetized on Day 4 and a ventral mid-sagittal incision was made to expose the uterine horns. An injection of $0.01 \mathrm{ml}$ antiserum to purified uterine peptidase was made into one uterine horn and $0.01 \mathrm{ml}$ normal rabbit serum was injected into the contralateral horn. The animals were killed on Day 10 and the number of implantations and corpora lutea on each side were counted.

\section{Results and Discussion}

In Exp. 1 bright fluorescence was observed surrounding the zona pellucida of the experimental egg (Pl. 1, Fig. 1) while no such fluorescence was seen on the control egg (Pl. 1, Fig. 2).

On Days 5 and 6 of pregnancy (Exp. 2), specific fluorescence in the endometrial glands was observed (Pl. 1, Fig. 3) and the epithelial cells of the uterine end of the oviduct also exhibited strong immunofluorescence (Pl. 1, Fig. 4). Sections of the ovary, vagina, pancreas, and spleen did not react, indicating absence of the endopeptidase.

In Exp. 3 injection of antiserum to the endopeptidase caused a significant decrease $(P<0.001$, $\left.\chi^{2}\right)$ in the number of implantations $(0.8 \pm 0.2$ (S.E.M.), $N=17)$ when compared to the number in the contralateral control horn $(5 \cdot 2 \pm 0 \cdot 7)$. The control horn exhibited an implantation ratio (no. of implantations/no. of corpora lutea) of $76 \%$ compared to $12 \%$ in the experimental horn, but there was no difference in the ovulation number on each side $(6.9 \pm 0.7$ and $7 \cdot 1 \pm 0.5$ corpora lutea, respectively).

The introduction of an antiserum to the uterine peptidase into the uterine horns of rats before implantation produced a significant reduction of implantation sites, indicating a role for this enzyme in implantation. The rat uterine-specific peptidase is oestrogen-dependent (Joshi \& Murray, 1974)and its appearance in the uterine glands on Days 5 and 6 of pregnancy is presumably due to the oestrogen surge which takes place on Day 4 (Shaikh \& Abraham, 1969; Waynforth, Pope \& Hosking, 1972) and is known to be necessary for implantation (Shelesnyak, Kraicer \& Zeilmaker, 1963; Yasukawa \& Meyer, 1966).

Implantation comprises a series of events involving changes in the uterine epithelium and in the blastocyst. In the mouse and rat (Nilsson, 1966), and in other animals (Schlafke \& Enders, 1975), invasion of the uterine epithelium by the blastocyst is preceded by increased adhesiveness of the uterine epithelium, a process in which lytic enzymes may be involved. Lytic enzymes have also been implicated in lysis of the zona pellucida, a necessary prerequisite to implantation. McLaren (1970) has suggested that an oestrogen-dependent zona lysin may be secreted by the uterus in the mouse. In the rat, blastocyst transfer experiments of Dickmann \& Noyes (1961) and Dickmann (1968) indicated that zona lysis was a result of secretion by the blastocyst.

Our results suggest that, during the passage of the zygote through the uterine portion of the oviduct, the peptidase in the oviductal secretion may be initiating the process of dissolution of the zona pellucida and that final rupture and dissolution of the zona is completed by the peptidase in the uterus. The final dissolution of the zona pellucida may be assisted by the secretion of the fully mature blastocyst.

We thank Mr Jack Illari for his invaluable photographic assistance and Mrs F. Gans for typing the manuscript. The contribution of M.G.R. constitutes part of the requirements for the Ph.D. degree of the Graduate School of Downstate Medical Center.

\section{References}

DickmanN, Z. (1968) Does shedding of the zona pellucida by the rat blastocyst depend on stimulation by the ovarian hormones? J. Endocr. 40, 393-399.
Dickmann, Z. \& Noyes, R.W. (1961) The zona pellucida at the time of implantation. Fert. Steril. 12, 310-318. Joshi, M.S. \& MưRAY, I.M. (1974) Immunological 
PLATE 1
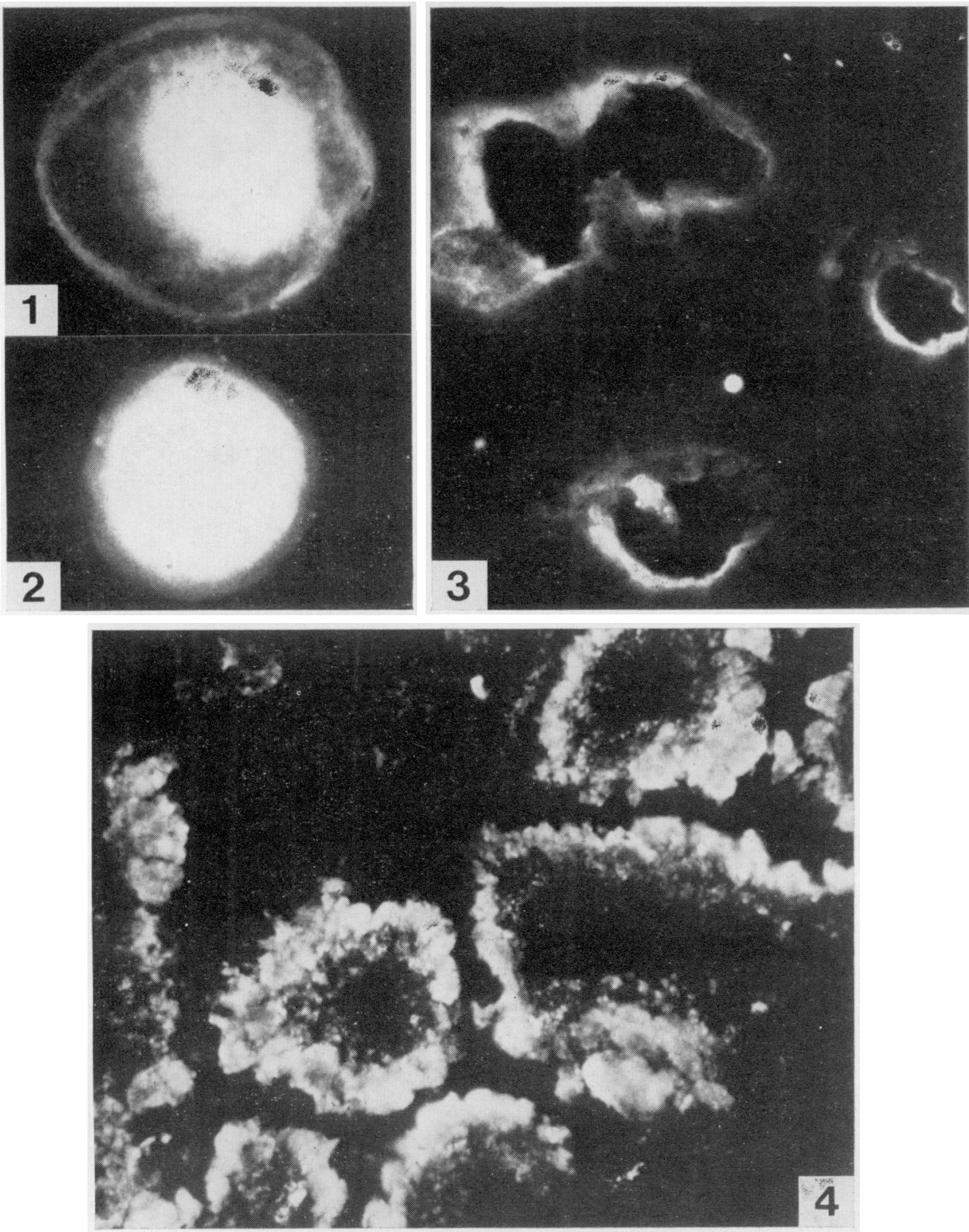

Fig. 1. A rat egg showing fluorescence of the zona pellucida after incubation with the purified peptidase. $\times 540$.

Fig. 2. A rat egg incubated in medium which did not contain the peptiuase, $\times 540$.

Fig. 3. Photomicrograph of the uterus of a 5-day-pregnant rat, showing the fluorescence in the gland cells. $\times 580$.

Fig. 4. Photomicrograph of the oviduct of 6-day-pregnant rat, showing the presence of fluorescence in the epithelial cells. $\times 720$. 
studies of the rat uterine fluid peptidase. $J$. Reprod. Fert. 37, 361-365.

Joshi, M.S. \& Rosenfeld, M.G. (1976) Hormonal influence on the appearance of uterine specific peptidase in the rat and mouse. In Protides of the Biological Fluids, Vol. 24, pp. 109-112. Ed. H. Peeters. Pergamon, Oxford.

Joshi, M.S., Yaron, A. \& Lindner, H.R. (1970) An endopeptidase in the uterine secretion of the proestrous rat and its relation to a sperm decapitating factor. Biochem. biophys. Res. Commun. 38, 52-56.

LonG, J.A. \& Evans, H.M. (1922) The oestrous cycle in the rat and its associated phenomena. Mem. Univ. Calif. 6, 1-148.

Lowry, O.H., Rosebrough, N.J., FARR, A.L. \& RANDALL, R.J. (1951) Protein measurement with the Folin phenol reagent. J. biol. Chem. 193, 265275.

MCLAREN, A. (1970) The fate of the zona pellucida in mice. J. Embryol. exp. Morph. 23, 1-19.

NAIRN, R.C. (1969) Immunological tracing: general consideration. In Fluorescent Protein Tracing, p. 111 Ed. R. C. Nairn. Williams \& Wilkins, Baltimore.

Nrusson, O. (1966) Estrogen-induced increase of adhesiveness in uterine epithelium of mouse and rat. Expl Cell Res. 43, 239-241.
SCHLAFKe, S. \& ENDERS, A.C. (1975) Cellular basis of interaction between trophoblast and uterus at implantation. Biol. Reprod. 12, 41-65.

ShaIKH, A.A. \& ABRAhaM, G.E. (1969) Measurement of estrogen surge during pseudopregnancy in rats by radioimmunoassay. Biol. Reprod. 1, 378-380.

Shelesnyak, M.C., KRAICer, P.F. \& ZeIlmaker, G.H. (1963) Studies on the mechanism of decidualization. 1. The estrogen surge of pseudopregnancy and progravidity and its role in the process of decidualization. Acta endocr., Copenh. 42, 225232.

Toyoda, Y. \& Chang, M.C. (1974) Fertilization of rat eggs in vitro by epididymal spermatozoa and the development of eggs following transfer. J. Reprod. Fert. 36, 9-22.

WARREN, M.R. (1938) Observations of the uterine fluid of the rat. Am.J. Physiol. 122, 602-606.

WAYNForth, H.B., POPE, G.S. \& Hosking, Z.D. (1972) Secretion rates of oestrogens into the ovarian venous blood of pregnant rats. J. Reprod. Fert. 28, 191-196.

YasUKaWA, J.S. \& MEYER, R.K. (1966) Effect of progesterone and oestrone on the pre-implantation and implantation stages of embryo development in the rat. J. Reprod. Fert. 11, 245-255.

Received 31 January 1977 